IVETE LARA CAMARGOS WALTY*

MARIA HELENA RABELO CAMPOS*

RESUMO

Ao analisar diversos textos que retomam o "Poema de sete faces" de Drumond, este trabalho es tabelece relaçöes entre o processo da intertextualidade $e$ o mito do eterno retorno, discutindo os limites entre homem arcaico e homem moder no, mito e histōria, imitação e transgressão.

o homem está sempre escrevendo un unico e mesmo texto. Tal afirmação de Borges nos levou a associar o processo inter textual ao mito do eterno retorno.

Que forças levam o homem a essa permanente retomada de textos primordiais, na tentativa de uma sempre nova cosmogonia, ato criador que se quer repetição do gesto inaugural, sa grado? Diz Mircea Ellade que o "homem arcaico apenas conhece os atos que já foram vividos anteriormente por outros, um outro que nāo era um homem. Tudo o que ele faz já foi feito. A sua vida è uma repetição ininterrupta de gestos inaugurados por outros". 1

Numa primeira perspectiva, o homem buscaria o caminho pa ra o "si", para o "centro" do seu ser. Caminho árduo, perigoso-passagem. 0 acesso ao centro corresponde a uma consagração?

o homem estaria sempre a imitar ou repetir um arquétipo, atravēs de rituais que, abolindo o tempo, lhe permitiam uma volta ao tempo do princípio, "ab origine".

Tal procedimento seria apenas do homem arcalco? Como se coloca o homem moderno, dlante desse movimente continuo de volta a um centro que o sacralize? A relação entre o homem ar calco e o homem moderno nos coloca no terreno do mito e da histōria. A partir das considerações do próprlo Eliade, perce

*Professoras Adjuntas de Teoria da Literatura da Faculdade de Letras da UFMG

o Eixo e a Roda, Belo Horizonte, (4): p. 71-87, 1985. 
bemos que os limites entre mito e história não são ríg1dos.Io go, não o são tambēm os que separariam o homem arcalco e o mo derno.

Analisemos un pouco mais essa idéia. Un traço recorrente em todos os mitos cosmogônicos é a criação do mundo pelo poder do Verbo, o que Derrida chamou fonocentrismo. 3 Dessa for ma, o mito será preso a un centro, origem de todas as coisas tendo no rito sua força centrifuga.

A época moderna, através da socłologia, da psicanálise, da antropologia ou da economia politica, faz uma revisão do logocentrismo. Atitude desmitificadora, descentralizadora, pro pondo uma nova visão da história.

Destituído de seu centro, o homem deixarla de repetir, de imitar, para transgredix.

No terreno da intertextualldade, A.R. de Sant'Anna ${ }^{4}$ trabalha as oposiçōes centramento/descentramento associadas às categorias da parăfrase e da parödia. A primelra se relacionaria à repetição, à imitação' enquanto que a segunda teria no descentramento seu parâmetro.

Depols de tais consideraçōes, resta-nos a pergunta: imitação e transgressão são realmente duas categorias opostas?

$A$ anālise de seis poemas de autores contemporâneos ${ }^{5}$ nos possibilita repensar as questōes da intertextualidade, suas relações com o mito e a histōria, com o sagrado e o profano, com o centramento e o descentramento.

o texto bíblico da anunciação $\bar{e}$ o ponto de recorrência entre esses poemas. E o primeiro aspecto que se nos apresenta é o da sacralização e dessacralização. Dentre os poemas de que nos ocupamos, o de Carlos Drummond de Andrade $\bar{e}$ o que pr1 meiro transgride e dessacraliza o texto biblico.

Nas Sagradas Escrituras encontramos:

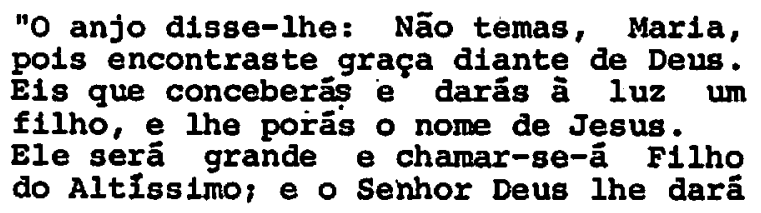

O Eixo.e a Roda, Belo Horizonte, (4): p. 71. $87,1985$. 
- trono de seu pal Davi; e reinará eternamente na casa de Jacó e o seu reinado nāo terā fim".

(Lucas $1 ; 30$ )

Drummond, em "Poema de sete faces", não sō retira o texto de seu espaço sagrado como tambēm se afasta do modelo proposto. Nele, o anjo, antes que ser luminoso, anunciador de boas novas, e- um "anjo torto" que vive "na sombra" e que pronuncia não o caminho da grandeza e da glörla, mas a marginalidade do homem e do poeta. Retoma assim outro texto biblico: o da expulsão dos anjos do paralso e, por extensāo, da queda do homem por causa do pecado. o anjo anunciador de Drummond é um anjo decaido.

Entretanto, "gauche", anjo decaido, o poeta oscila entre - modelo divino e o seu avesso. o espaço harmōnico do paraíso é substituío pela cidade grande, habitada pelo homem, habita do pelo desejo.

Expressão da falta primordial, o desejo, Inerente à condição humana, se constitul no móvel do homem e do texto:

"A tarde talvez fosse azul Não houvesse tantos desejos".

Conflgura-se ai un diālogo entre o mito e a histōria. A perda do centro deixa o homem desvalido, confuso, perdido de si, diante do social e da história.

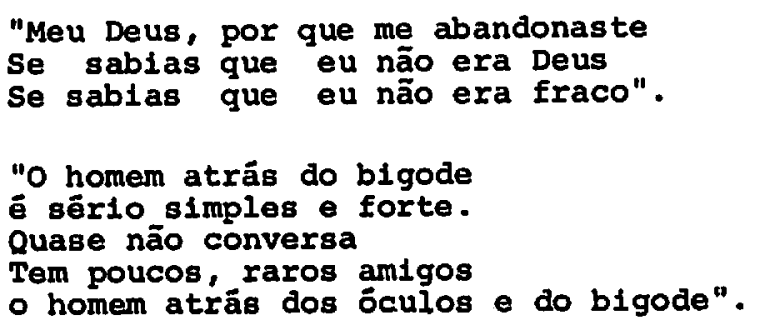

A figura de Cristo na cruz chamando a Deus diante do sen timento de abandono è subjacente à figura do homem-poeta, revoltado diante da impotêncla em que se encontra. A representa 
ção social jã não the basta.

Ao confessar-se, o homem deixa cair a máscara. A palavra è o meio flisico de resgate da unidade perdida, da harmonia quebrada. Paradoxalmente, a rima faz-se solução. $O$ verbo reinstaura o tempo do principio, e o poema faz-se cosmogonia.

Dessacralizador, o texto de Drummond faz-se sagrado e $\bar{e}$, com licença poêtica, que Adélía Prado dele se aproxima.

Rompendo com o texto que the serve de modelo, Adēlia Pra do retoma o texto biblico alçando a condição humana, em especlal a feminina, à condição divina. o anjo sai da sombra e so bressai como anunclador de boa nova. Recupera-se o arquétipo.

Pelas mãos da condição feminina, a histōria revisita e revivifica o mito. Consciente do lugar social da mulher, "espēcle ainda envergonhada", a poeta faz de seu poema sua bandelra de defesa.

Ao contrário de Drummond que tenta reprimir o desejo

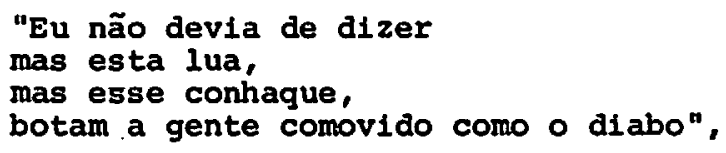

Adélia explicitamente assume 0 desejo e reltera sua divindade.

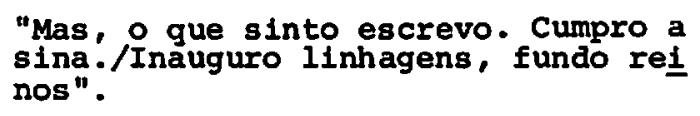

A condição de poeta, ser crlador, alia-se a condição feminina na confessada dicotomia homem/mulher, Drummond/Adélia, anjo torto/anjo esbelto.

\footnotetext{
"Vai ser coxo na vida, è maldição pra homem.

Mulher è desdobrável. Eu sou".
}

o verbo ser, usado intransitivamente, reinstaura a supremacia do verbo, sopro divino gerador de vida. Reinaugura-se o fonocentrismo.

Mas, mesmo a tentativa de transgredir o primeiro modelo tomado, o texto de Drummond, num retorno ao texto primordial, não leva Adëlia a um efetivo rompimento.

O Eixo e a Roda, Belo Horizonte, (4): p. $71-87,1985$. 
Seu texto è, sobretudo, uma forma de paródia diferente da tradicional. Antes que ridicularização do texto anterior, - novo poema presta-1he "respeitosa homenagem" que vem disfar çada por um "curioso nariz de cera" o que, em ültima instāncia, tem a função de diluir "a ansiedade de influência".?

Drummond reafirma-se como modelo, imagem de poder e auto ridade, a quem se pede licença para questionar.

A figura do poder se faz desafio também para Chico Buarque em "Até o fim". Dessa felta, ao poder sagrado se alia o poder polftico, numa contextualização social da vida brasilei ra dos anos 70 .

o anjo é agora "safado", "o chato dura querubim", aquele que, na hierarquia dos anjos, representa o guardião da lei.Fo ram querubins que, com sua espada flamejante, guardaram o caminho da ärvore da vida, impedindo o homem de voltar ao jardìn do Eden apōs sua expulsāo. (Gen. 3, 23-24)

Paradigma do poder, 0 anjo não anuncia nada, mas "decreta" a expulsão do poeta da vida social. Seu instrumento já não è a trombeta, mas o clarim.

o anjo não è torto. Torta è a estrada, metäfora do traça do social, destino dos homens. A Indeterminação do sujeito nas frases seguintes revela a face impessoal do poder arbiträrio e forte. Os verbos "cassaram" e "quebraram" confirmam tal arbitrariedade. Mas, Insubordinadamente, o poeta recusa submeter-se ao destino que lhe foi traçado ao afirmar: "mas vou até o fim".

Rejeitando os modelos socials propostos pelo senso comum - a escola, a bola, o futuro promissor, o sucesso, a harmonia familiar, a acumulação do capital - o poeta faz do fracasso da vitima a denúncia do sistema que o marginaliza.

Recusando-se a ouvir o clarim, metonimia do canto marcial da ordem, o poeta, apesar do bandolim quebrado, grava no poema o seu canto de festim. Paradoxalmente, ao curmpir o des tino que lhe foi imposto: "ser errado assim", recusa-se a ser sacrificado e contraria este mesmo destino.

Anjo expulso, o poeta faz da sua resistência a possibili dade de retorno ao paraiso. Tambëm al a voz, ainda que "chin-

O Eixo e a Roda, Belo Horizonte, (4): p. 71-87, 1985 . 
frim", è o elemento de criação, marca que aproxima o homem de Deus.

Torquato Neto, em "Let's play that", explicita a função do poeta de "desafinar o coro dos contentes". Assume sua marginalidade e quer-se elemento desestruturador do sistema pol $\underline{1}$ tico-social. Tambēm aqui o anjo não anuncla, mas faz-se quiro mante, leitor do destino já traçado. A estranha modernidade de sua figura foge ao estereōtico biblico.

$$
\begin{aligned}
& \text { "nāo era um anjo barroco } \\
& \text { era um anjo muito louco, torto } \\
& \text { com asas de avião". }
\end{aligned}
$$

Diferentemente de Chico Buarque, que se opõe ao anjo, emissãrto do poder, Torquato Neto é cúmplice do anjo: "els que esse anjo me disse/apertando a minha mão". A ironia do sorriso entre dentes sallenta o lugar ocupado pelo poeta: aquele que tem poder para desafiar o poder. Na medida em que, via con testação, o poder se bifurca instaurando um poder paralelo, ele se afirma tendo no contestado seu modelo.

Assumindo a sua missão de desafinar/desafiar o senso comum, o poeta identifica-se com a figura do anjo e chama o le 1 tor, curiosamente, a integrar o seu coro.

Cada qual pede licença a seu modo. Sidnei olivio, em "An jo", o faz através das aspas e da referêncla explícita ao modelo Drummond, de novo aparentemente contestado. o anjo, agora, ora se aproxima, ora se afasta dos modelos tomados. Ele tem caracteristicas do anjo de Drumond e do de Torquato Neto, mas o poeta faz questão de salientar sua diferença.

A mistura de caracteristicas opostas e excludentes como "herōi" e "vilão", Intensifica o processo de carnavalização jā antevisto nos poemas anteriores atravēs da dessacralizaçāo. Observa-se ai o paradigma do anjo decaido, que assume a sua degradação e não parece se envolver nas questōes do poder. Ao se assumir como anjo decaldo,

\footnotetext{
"E eu cai na ribanceira num tropeço da fogueira me esborrachel no chão... Na pista do aeroporto
}

o Eixo e a Roda, Belo Horizonte, (4): p. $71-87,1985$. 
foi onde acharam meu corpo sobre um rastro de avião... Não sei o que aconteceu mas acho que esse anjo era eu... Flcou uma pena no chăo".

- poeta assume a condição humana e suas contradiçōes, denominando-se barroco.

Esta caracteristica, barroco, surge como o ponto nodal de um ser que, anjo, não elimina sua modernidade. Ao assumila, condensa em si os traços do humano e do dlvino, num processo ambivalente que marca sua historicização.

Mas contradição e ambivalência deixam à vista aquilo que nem sempre é de se ver e dizer. Daí a razão da máscara, do dis farce, da farsa, da representação a que tambēm nos remete 0 texto de Drummond: "O homem atrás dos óculos e do bigode".

A máscara revela-se, portanto, algo inerente ao ser huna no e, ao denunciá-la, mesmo sem a concorrência da "lua" e do "conhaque", o poeta se desnuda diante do leitor.

A sexual1dade, maxca do anjo "tarado" e "gavião", acentua a ambigüidade da figura humana na terra, entre 0 inferno e o paraiso que o poeta afirma sem julgar ou exorcizar.

Apesar de "cartomante" e "cigano", ele não se quer mensa geiro ou emissārio do Verbo, divino ou demoníaco.

Afirma antes sua incompetência de anjo "manco", "quase morto", "rouco", revelando a falta, a carência prōpría da con dição humana, representada no verso "Ficou uma pena no chão". A palavra pena, metonimia/metăfora do anjo è, ao mesmo tempo, traço do sofrimento do homem fora do paraíso.

A voz - o Verbo - origem e missāo do anjo parece emude cer: "não me disse nada não".

Fica a pergunta: e a voz do poema?

Retomando o "Poema de sete faces" de Drummond, Marla das Graças Paulino, com "Aquelas sete faces", fecha o ciclo do eterno retorno na medida em que mostra o homem na sua caminhada da degradação para a condição divina, origem da criação.

Ao falar do poema como ritual que re-atualiza a cosmogonia, a posta recupera o verbo e reinstaura o fonocentrismo.

O Eixo e a Roda, Belo Horizonte, (4): p. $71-87,1985$. 
Observe-se a gradação estabelecida nas sete faces do poe ma. Da contınuação demoníaca de anjo decaldo, geradora de desordem e de caos, passa-se à condição ambigua de lobisomem. Do caos indiferenciado, do afastamento ou da negação da face de Deus, o ser se conströi, pouco a pouco, à imagem e semelhança de Deus. E por isso que a terceira face é a "pura máscara do ser" quando, atravēs da representação, se instaura a condição humana, acentuada na etapa seguinte por seu caräter perecivel:

$$
\begin{aligned}
& \text { "e como tampar a quarta } \\
& \text { de cinzas santas } \\
& \text { se virá pó, e pó lerăs?" }
\end{aligned}
$$

A menção ao texto bíblico, que fala da morte do corpo, marca $\circ$ momento de transição da condiçāo humana à cond1ção di vina. A face da mãe, ligada à idêia da pureza infantil, jä prenuncla a face de Deus. Não se pode delxar de fazer uma referência ao texto lacaniano ${ }^{7}$ no que se refere à fase do espetho quando a criança, rompendo a relaçāo dual com a mãe, encontra sua pröpria 1dentidade, assume sua Imagem, a partir da presença do Outro.

No poena, o homem reencontra na face da mãe, "face mansa", o espaço harmônico, uterino, paradisiaco. Aqui, a 1dentı ficação do homem a Deus não se dã através de sua imagem fís1$\mathrm{ca}$, mas justamente através do seu despojamento, is to é, de sua marca terrena.

Com efelto, a sétima face funde e anula todas as outras numa sō, a face de Deus. Dá-se a purificação. O homem livrase do pecado, da loucura porque se iguala a Deus através do poetar. O uso Inusitado da segunda pessoa verbal "aquele que fazes/Senhor de todas as falas": exime a poeta da responsabilidade de tal afirmação na medida em que a transfere para um terceiro, quem sabe o le1tor, quem sabe outros poetas, ou 0 ser humano. No fundo, consciente ou inconscientemente, a afir mação está feita e não hã como fugir dela: retorna-se ao verbo primordial a "face de Deus", "Senhor de todas as falas": e o "primeiro verso a flcar".

A anålise desses poemas nos aponta uma resposta possivel para a pergunta que formulamos inicialmente: Imitação e trang O Eixo e a Roda, Belo Horizonte, (4): p. $71-87,1985$. 
gressão são duas categorias opostas a se excluirem mutuamente? Seria o mito a simples repetição e a História a possibilidade da transgressão?

Observamos que os poemas, inseridos na História, a trans cender e remetem ao tempo do principlo, tempo arquetíplco, en quanto ato de criação que, por sua vez, marca algo único e $1 \underline{r}$ repetivel.

Octāvio Paz nos fala que esta è a função da poesia já que "a condição dual da palavra poética não é diferente da na tureza do homem, ser temporal e relativo, mas sempre lançado ao absoluto", num "transcender-se sem cessar no qual reside precisamente sua liberdade essencial". 8

o mito do eterno retorno nasce da marca do homem, da fal ta, da carēncia que o impulsionam na busca da superação de seus limites: sua condiçāo histórica.

Dessa forma, coletivo e individual, sagrado e profano, mi to e históría não são categorias isoladas, mas coexistem em tensāo dialética. O fenômeno da intertextualidade explicita essa interaçāo atravēs do diālogo que estabelece entre essas diversas categorias.

Ao construir o poema, o homem, ao mesmo tempo em que se insere na História, reatualiza a cosmogonia.

Resta-nos ainda perguntar qual o papel do leitor ao reto mar, por sua vez, os textos do outro? Estaremos diante de outra dicotomia: autor/leitor, poema/leitor?

Responder a estas questōes é retornar às consideraçōes anteriores, pois, como diz octávio paz, o leitor também faz un poema que, como toda recriação, "não é o duplo exato do es crito pelo poeta. Mas se não è idêntico quanto a isto e aqui10, è 1dêntico quanto ao próprio ato da criação: o leitor recria o instante e cria-se a si mesmo".

Drummond, Adêlia, Chico, Torquato, Sidnel Olfvio e Graça Paulino, autores-leitores tecem um texto que, tela, se tece e se desfaz a cada instante, rede a prender e soltar poetas e leitores. No fim "existe ë homem humano"9 a revelar/purgar sua condição.

O Eixo e a Roda, Belo Horizonte, (4): p. 71-87, 1985. 
POEMAS ANALISADOS

POEMA DE SETE FACES

Quando nasci, um anjo torto

desses que vivem na sombra

disse: val, Carlos! ser gauche na vida.

As casas espian: os homens que correm atrás de mulheres.

A tarde talvez fosse azul, não houvesse tantos desejos.

O bonde passa chelo de pernas: pernas brancas pretas e amarelas Para que tanta perna, meu Deus, pergunta meu coração. Porém meus olhos não perguntam nada.

O homem atrās do bigode

é serio, simples e forte. Quase não conversa.

Tem poucos, raros amigos

o homem atrās dos óculos e do bigode.

Keu Deus, por que me abandonaste se sabias que eu não era Deus se sablas que eu era fraco.

Mundo mundo vasto mundo.

Se. eu. me chamasse Raimundo seria uma rima, não sería uma solução. Mundo mundo vasto mundo, mais vasto è meu coração.

O Eixo e a Roda, Belo Horizonte, (4): p. $71-87,1985$. 
Eu näo devia te dizer mas essa lua

mas esse conhaque

botam a gente comovido como o diabo.

ANDRADE, C. Drummond. Obra Completa. Rio de Janeiro, Aguílar, 1967. p. 53.

O. Eixo e a Roda, Belo Horizonte, (4) : p. $11-87,1985$. 
COM IICENÇA POETICA

Quando nascl um anjo esbelto, desses que tocam trombeta, anunciou: vai carregar bandelra.

Cargo multo pesado pra mulher, esta espécle ainda engergonhada. Acel to os subterfúgios que me cabem, sem precisar mentir.

Não sou tão fela que não possa casar, acho o Rio de Janeiro uma beleza e ora sim, ora nāo, crelo em parto sem dor. Mas, o que sinto escrevo. Cumpro a sina. Inauguro linhagens, fundo reinos (dor não é amargura). Minha tristeza não tem pedigree, jã a minha vontade de alegria, sua raiz vai ao meu $\mathrm{mil}$ avô. Vai ser coxo na vida, è maldição pra homem. Mulher é desdobrãvel. Eu sou.

PRADo, Adélia. Bagagem. Rio, Nova Fronteira, 1979. p. 19.

ATE O FIM

Quando nascl velo um anjo safado

o chato dum querubim

E decretou que eu tava predestinado

A ser errado assim Jå de saída a minha estrada entortou Mas vou atë o flm Inda garoto delxel de ir à escola Cassaram meu boletim Não sou ladrão, eu não sou bom de bola Nem posso ouvir clarim 
Un bom futuro é o que jamais me esperou Mas vou atē o fim

Eu bem que tenho ensaiado um progresso

Virel cantor de festim

Mamäe contou que eu faço un bruto sucesso

Em Quixeramobim

Não sel como o maracatu começou

Mas vou atē o fim

Por causa de umas questōes paralelas

Quebraram meu bandolim

Não querem mais ouvir as minhas mazelas

E a.minha voz chinfrim

Criel barriga, minha mula empacou

Mas vou atè o fim

Nāo tem cigarro, acabou minha renda

Deu praga no meu capim

Minha mulher fugiu com o dono da venda

o que será de mim?

Eu jä nem lembro pronde mesmo eu vou

Mas vou atē o fim

Como já disse, era um anjo safado

o chato dum querubim

Que decretou que eu tava predestinado

A ser todo ruim

Já de saida a minha estrada entortou

Mas vou até o fim

HOLANDA, Chico Buarque de. In: -

A arte de Chico Buarque. Rio de

Janeiro, Polygram, 1982. 


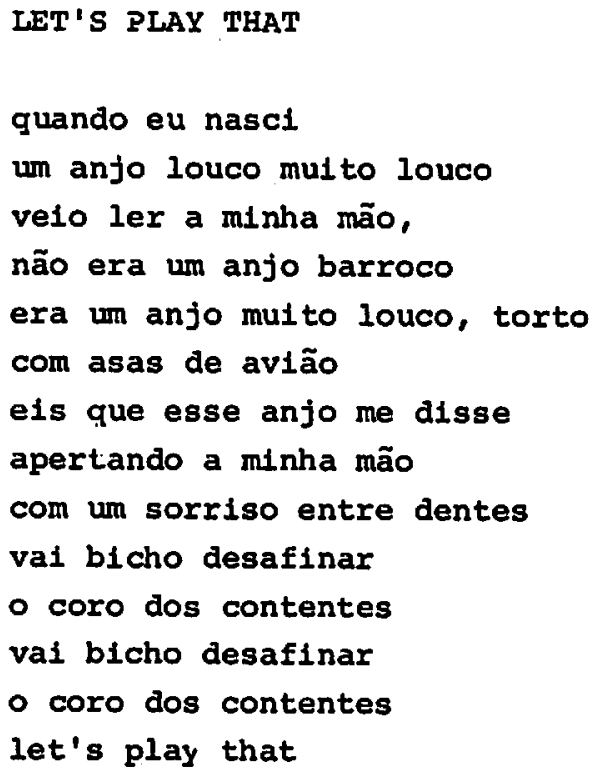

TORQUATO NETO. Os ültimos dias de Pompéía. Org. Ana Maria S. Duarte e Wely Salomão, 1a ed. Ed. Mod Limoned,1982.

ANJO

"Quando nasci, um anjo torto", manco quase morto, veio ler a minha mão. Era un anjo muito torto, torto, torto, mas era muito diferente, é claro do anjo de Drummond.

Era un anjo bem barroco

rouco, rouco, rouco com asas de avião...

Era um anjo disfarçado

pirado, endiabrado, era um anjo beberrão...

Era un anjo muito pouco

O Eixo e a Roda, Belo Horizonte, (4): p. $71-87,1985$. 
louco, louco, louco, solto na imensidão... Era um anjo mascarado, heröi, cruel, tarado um anjo gavião.

E eu caí na ribanceira num tropeço da fogueira me esborrache1 no chão... $\mathrm{Na}$ pista do aeroporto foi onde acharam meu corpo sobre um rastro de avião... Não sei o que aconteceu mas acho que esse anjo era eu... Ficou uma pena no chão.

Era um anjo cartomante, um cigano, um farsante não sacava de ler mão... Era um anjo incompetente, vilão, indiferente, não me disse nada não...

$$
\begin{aligned}
& \text { OLIVIo, Sidney. Anjo. In:-. Anjo. } \\
& \text { São Paulo, Grupo Realejo, } 1985 .
\end{aligned}
$$

\section{AQUELAS SETE FACES}

Se poetas tềm sezão

as faces do poema são sete:

a primelra, tentação,

- diabo rimou e comerá;

a segunda, ensandecida, na lua cheia, uivos; terceira parece nada pura mäscara do ser; e como tampar a quarta 


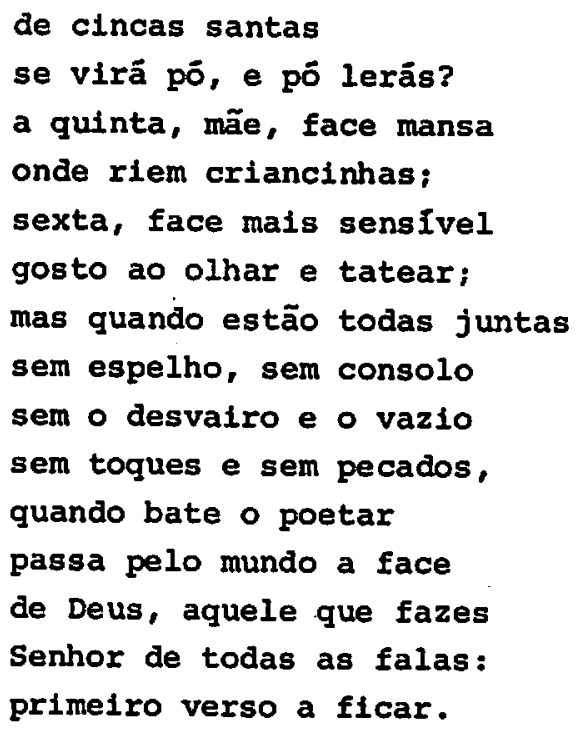

PAULINo, Maria das Graças R. Ensaios de semiōtica. Cadernos de Lingüistica e Teoria da Literatura. N8 12. Belo Horizonte, Imprensa Universitá ria, FALE-UFMG, 1984. p. 231.

NOTAS

1. ElIADE, Mircea. O mito do esterno retorno. Lisboa, Ediçōes 70, 1978. p. 19 .

2. Idem, ibidem, p. 33 .

3. DERRIDA, Jacques. o fim do livro e o começo da escritura. In:- Gramatologia.são Paulo, Perspectiva, 1973. p. 7-32.

4. SANT'ANNA, Affonso R. Modernismo: as poēticas do centramento e do descentramento. In: AVILA, Affonso. 0 modernismo. São Paulo, Perspectiva, 1975. p. 55-68.

O Eixo e a Roda, Belo Horizonte, (4): p. $71-81,1985$. 
5. Os textos analisados são: Poema de sete faces - Drumnond, Com licença poëtica - Adēlia Prado, Até o fim - Chico Buar que, Let's play that - Torquato Neto, Anjo - Sidney Olivio e Aquelas sete faces - Maria das Graças R. Paulino.

6. HUTCHEON, Linda. Ironie et parodie: stratëgie et structure. In: - Poētique: revue de thēorie et d'analyse littéraires. p. 467 e 476 .

7. LACAN, J.J. Le stade du miroir comme formateur de la fonc tion du je. In: - Ecrits I. Paris, Seuil, 1966. p. 89 97.

8. PAZ, Octävio. O arco e a lina. Rio de Janeiro, Nova Fronteira, 1982. p. 231-232.

9. ROSA, Joāo Guimaräes. Grande sertão: veredas, 10 a ed., Rlo de Janeiro, Livr. José Olympio. 1976. p. 460. 